\title{
The Regularities of Coordination Reaction between Cobalt(III) 5,15-Diphenyloctaalkylporphyrin and Organic Bases
}

\author{
Svetlana V. Zaitseva, ${ }^{a}{ }^{@}$ Sergey A. Zdanovich, ${ }^{\mathrm{a}}$ and Oscar I. Koifman ${ }^{\mathrm{a}, \mathrm{b}}$ \\ ${ }^{\mathrm{a}}$ G.A. Krestov Institute of Solution Chemistry of Russian Academy of Sciences, 153045 Ivanovo, Russia \\ ' Ivanovo State University of Chemistry and Technology, 153000 Ivanovo, Russia \\ ${ }^{\circledR}$ Corresponding authorE-mail: svz@isc-ras.ru
}

\begin{abstract}
The process of molecular interaction of cobalt(III) porphyrinates with small organic molecules was studied spectrophotometrically and by quantum-chemical PM3 method. The reaction regularities and stability constants of molecular complexes were determined in benzene. Geometry and energy characteristics of the optimized cobalt porphyrinates molecules and their molecular complexes were calculated, as well as the degree of their deformation. It was found, that in the course of intermolecular interaction the deformation of porphyrin ligand is changed. The dependencies between the calculated and experimental data are discussed.
\end{abstract}

Keywords: Porphyrin, complex, cobalt, coordination, structure.

\section{Закономерности реакции координации}

\section{5,15-Аифенилпорфиринатом кобальта органических оснований}

\author{
С.В. Зайцева, ${ }^{a}$ С.А. Зданович, ${ }^{a}$ О.И. Койфрман ${ }^{\text {a,b }}$ \\ ${ }^{\mathrm{a}}$ Институт химии растворов им. А.Г. Крестова РАН, 153045 Иваново, Россия \\ ${ }^{\mathrm{b}}$ Ивановский государственный химико-технологический университет, 153000 Иваново, Россия \\ @E-mail: svz@isc-ras.ru
}

\begin{abstract}
Проиесс межмолекулярного взаимодействия порфирината кобальта(III) с мальми органическими молекулами исследован спектрофотометрически и квантово-химическим методом РМЗ. Установлены закономерности исследуемой реакции. Определены устойчивость и тип структуры молекулярных комплексов в бензоле. Рассчитаны геометрические и энергетические характеристики оптимизированных молекул порфирината кобальта и его молекулярных комплексов. Оиенена их степень деформащии. Установлено, что в ходе межмолекулярного взаимодействия происходит изменение деформации порфиринового лиганда. Получены зависимости между расчетными и экспериментальными данными.
\end{abstract}

Ключевые слова: Порфирин, комплекс, кобальт, координация, структура.

\section{Введение}

Каталитические, сенсорные и другие свойства порфиринаты металлов проявляют в основном в составе более сложных координационных соединений. [1-3] Одним из важнейших образований этого типа, формирующихся и функционирующих в каталитических и ферментативных системах, являются аксиальные комплексы порфиринатов высокозарядных металлов. Поэтому, в настоящей работе, в рамках исследования координационных свойств порфиринатов металлов, методом спектрофотометрического титрования ${ }^{[4]}$ и компьютерного моделирования ${ }^{[5-8]}$ изучен процесс связывания 5,15 -дифенил-октаалкилпорфиринатом кобальта(III) ((Ас)СоР) малых органических молекул в бензоле.

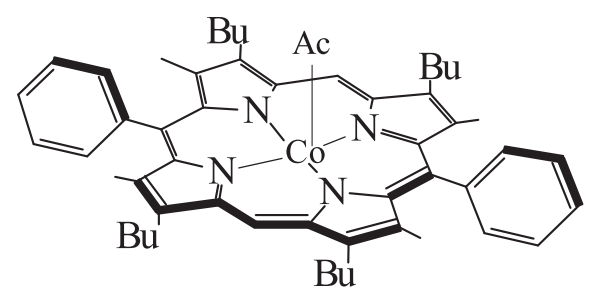

(Ac) $\mathrm{CoP}$ 


\section{Экспериментальная часть}

Константу равновесия (устойчивости) межмолекулярного взаимодействия определяли по уравнению для равновесной системы ${ }^{[9]}$ при 298 К в бензоле.

Электронные спектры поглощения (ЭСП) снимали на спектрофотометре Cary-50 в диапазоне от 380 до 700 нм. Оптическая плотность для серии растворов при постоянной концентрации порфирината кобальта и различных концентрациях основания регистрировалась на рабочих длинах волн 405-437 нм, в кюветах толщиной 1 см. Погрешность термостатирования не больше 1 К. Оптимизацию величин $K_{\mathrm{p}}$ с определением средних квадратичных отклонений проводили по методу наименьших квадратов с использованием программы Microsoft Excel. Относительная ошибка в определении искомых величин составила 3-10\%.

Квантово-химические расчеты выполнены методом PM3 ${ }^{[5-8]}$ с использованием РС-версии ${ }^{[10]}$ программного комплекса Gamess. ${ }^{[11]}$ Условием окончания счета являлся заданный градиент 0.001 кДж/(моль-А̊). Подготовку исходных данных и обработку результатов расчета проводили с помощью программы «ChemCraft» версия 1.3 (автор G.A. Zhurko). Для начального приближения были выбраны данные усредненной структуры металлопорфиринов, ${ }^{[12]}$ длины связей, углы для алкильных заместителей и органических оснований использовали из ${ }^{[13]}$. Ориентация ароматических оснований задавалась таким образом, чтобы атом азота с неподеленной электронной парой был направлен в сторону атома кобальта.

5,15 -Дифенил-2,8,12,18-тетраметил-3,7,13,17-тетрабутилпорфирин синтезирован и предоставлен проф. Семейкиным А.С. ${ }^{[14]}$ (ИГХТУ, г. Иваново)

Кобальтовый комплекс 5,15-дифенил-2,8,12,18-тетраметил-3, 7,13,17-тетрабутилпорфирина, (Ас)СоР. Порфиринлиганд $(0.1$ г) с десятикратным избытком ацетата кобальта $(0.27$ г) растворяли в 50 мл ацетонитрила и нагревали до кипения растворителя. Реакционную смесь кипятили в течение 2-2.5 часов. Контроль реакции проводили по изменению электронного спектра поглощения смеси. О полноте прохождения реакции судили по исчезновению полос поглощения порфирина и увеличению полос поглощения его кобальтового комплекса. После окончания реакции ацетонитрил отгоняли, сухой остаток растворяли в бензоле. Бензольный раствор промывали водой и упаривали. Комплекс очищали хроматографией на силикагеле (элюент - бензол) с последующей перекристаллизацией из хлороформа. Выход 95\%. Найдено: С 75.50, Н 7.39, N $6.52 \%$. $\mathrm{C}_{54} \mathrm{H}_{63} \mathrm{CoN}_{4} \mathrm{O}_{2}$ рассчитано С 75.70, Н 7.40, N $6.50 \%$. ЭСП (бензол) $\lambda_{\max }(\lg \varepsilon)$ нм: 561 (4.16), 532 (4.11), 405 (5.01). $\mathrm{R}_{f}$ (силуфол): 0.80 (бензол).

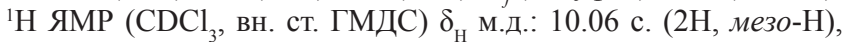
7.92 (д, 4H, орто-Н фенил), 7.71 (м, 6Н, мета-, napa-Н фенил), 3.93 (т, 8Н, $\mathrm{CH}_{2}$-бутильная группа), 2.72 (с, 3H, $\left.\mathrm{CH}_{3} \mathrm{CO}_{2}\right), 2.49$ (c, $12 \mathrm{H}, \mathrm{CH}_{3}$-метильная группа), 2.19 (т, 8Н, $\mathrm{CH}_{2}$-бутильная группа), 1.76 (м, 8Н, $\mathrm{CH}_{2}$-бутильная группа), 1.15 (т, 12H, $\mathrm{CH}_{3}$ бутильная группа).

\section{Результаты и обсуждение}

В ходе координации органических оснований $(\mathrm{L}=$ имидазол (Im), 2-метилимидазол(2-MeIm), пиридин (Ру), хинолин (Нi), диметилформамид (DMF)) порфиринатом кобальта наблюдается существенный сдвиг основных полос поглощения $(\Delta \lambda)$ его электронного спектра поглощения (ЭСП) (Рисунок 1). Величина сдвига колеблется от 21 нм до 29 нм. Реакция протекает по уравнению:

$$
(\mathrm{Ac}) \mathrm{CoP}+\mathrm{nL} \leftrightarrows(\mathrm{Ac}) \mathrm{Co}(\mathrm{L})_{\mathrm{n}} \mathrm{P}
$$

Состав комплекса определяли ограниченно логарифмическим методом (метод Бента-Френча) $)^{[4]}$ по тангенсу угла наклона $(\operatorname{tg} \alpha)$ линейной зависимости $\lg \left[\left(A_{\mathrm{p}}-A_{\mathrm{o}}\right) /\left(A_{\infty}-A_{\mathrm{p}}\right)\right]$ от $\lg C_{\mathrm{L}}$ (Рисунок 2$)$. Величина $\mathrm{n}$ для всех оснований составляет 0.8-1.2, что в пределах ошибки соответствует единице, и стехиометрия полученных комплексов 1:1.

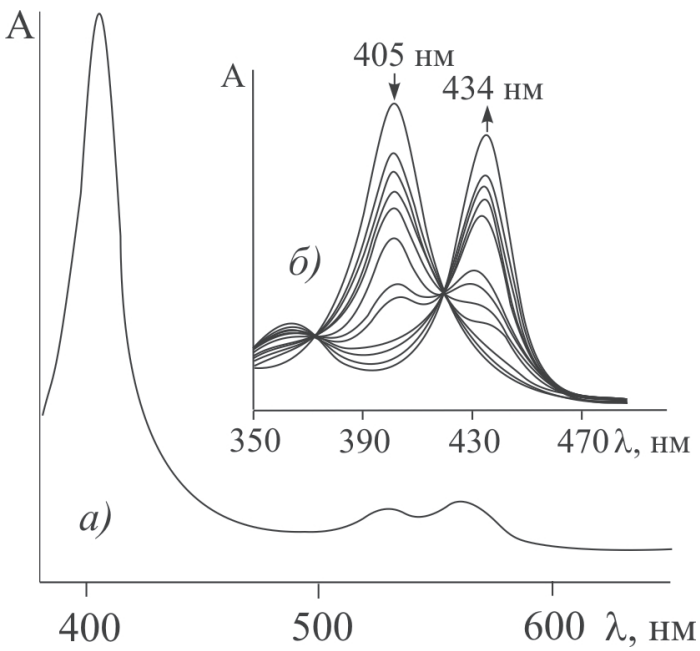

Рисунок 1. а) ЭСП (Ас)СоР ; б) изменение ЭСП (Ас)СоР (на примере полосы $B$ ) в реакции с имидазолом: 1 - (Ас)СоР $\left(C_{(\mathrm{Ac)} \mathrm{СоР}}=4.61 \cdot 10^{-6}\right.$ моль/л); 2-11 - (Ас)СоР с промежуточными концентрациями имидазола $\left(C_{\mathrm{Im}}=1.03 \cdot 10^{-5}-2.57 \cdot 10^{-4}\right.$ моль/л); 12 - (Ас)СоР с избытком имидазола $\left(C_{\mathrm{Im}}=1.07 \cdot 10^{-3}\right.$ моль/л) в бензоле.

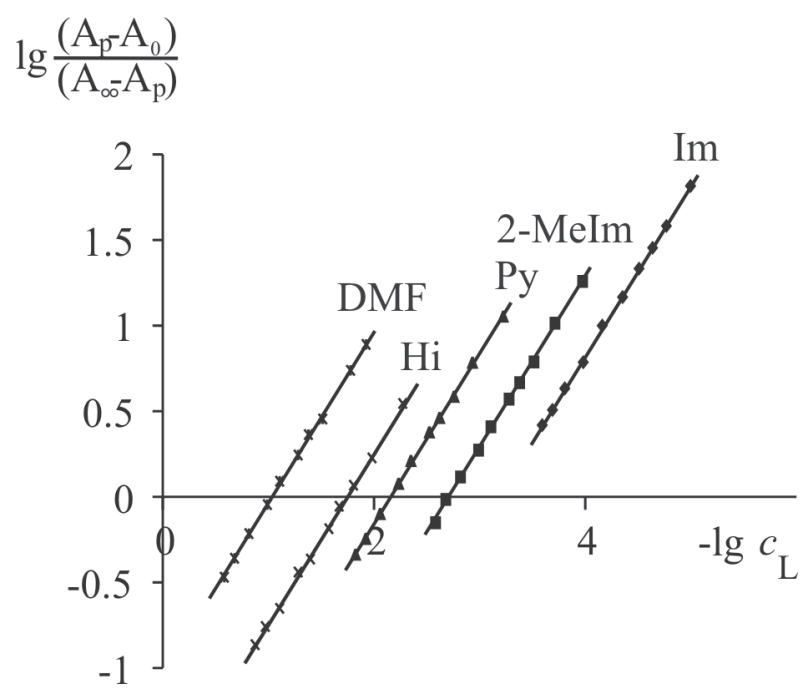

Рисунок 2. Зависимость $\lg \left[\left(A_{\mathrm{p}}-A_{\mathrm{o}}\right) /\left(A_{\infty}-A_{\mathrm{p}}\right)\right]$ от $\lg C_{\mathrm{L}}$ для реакции межмолекулярного взаимодействия (Ас)СоР с основаниями. $A_{\mathrm{o}}, A_{\mathrm{p}}, A_{\infty}$ - оптические плотности растворов на рабочей длине волны для металлопорфирина, равновесной смеси и молекулярного комплекса.

Анализ данных Таблицы 1 показывает, что устойчивость молекулярных комплексов порфирината кобальта растет в ряду оснований: DMF $<\mathrm{Hi}<$ Py $<2$-MeIm $<$ Im. Получена корреляция между значениями константы равновесия $\left(K_{\mathrm{p}}\right)$ и основностью малой органической молекулы (Рисунок 3). Основность характеризуется значениями $\mathrm{p} K_{\mathrm{a}}^{[15]}$ и сродством к протону $\left(E_{\text {прот }}\right)$ молекул 

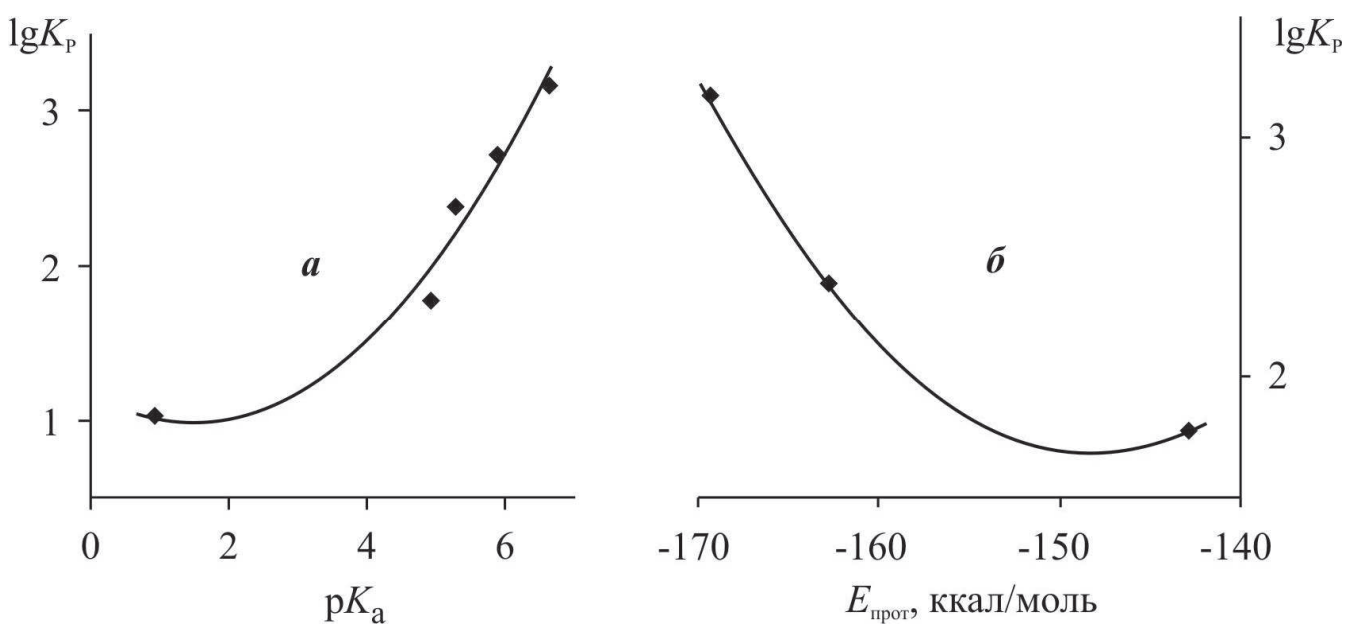

Рисунок 3. Зависимость устойчивости комплексов $(\mathrm{Ac})(\mathrm{L}) \mathrm{CoP}$ от значений $K_{\mathrm{a}}$ (а) и расчетной энергии протонирования органических оснований (б).

основания в газовой фазе, ${ }^{[16]}$ рассчитанным квантовохимическим методом $\mathrm{AM} 1^{[7]}$ (Таблица 1). Полученные значения $E_{\text {прот }}$ для хинолина и 2-метилимидазола не согласуются с данными $\mathrm{p} K$, что говорит об изменении донорно-акцепторных свойств аксиальных лигандов при переходе из водной в органическую среду. ${ }^{[16]}$ Следует заметить, что сродство к протону 2-MeIm выше, чем у Im, а у Ні выше, чем у Ру, однако устойчивость комплексов (Ac) $\mathrm{Co}(2-\mathrm{MeIm}) \mathrm{P} \mathrm{и}(\mathrm{Ac}) \mathrm{Co}(\mathrm{Hi}) \mathrm{P}$ ниже, чем у $(\mathrm{Ac}) \mathrm{Co}(\mathrm{Im})$ Р и $(\mathrm{Ac}) \mathrm{Co}($ Ру)Р, соответственно (Таблица 1). Причина такого несоответствия в том, что при аксиальной координации возникают стерические помехи со стороны $\mathrm{Hi}$ и 2-MeIm за счет их объемной структуры и наличия заместителя вблизи активного центра.

Таблица 1. Константы устойчивости молекулярных комплексов $(\mathrm{Ac}) \mathrm{Co}(\mathrm{L}) \mathrm{P}$ и расчетная величина энергии протонорования органических оснований (L).

\begin{tabular}{ccc}
\hline Комплекс & $K_{\mathrm{p}}^{298 \cdot 10^{-3}, \text { моль }^{-1} \cdot \text { л }}$ & $-E_{\text {прот }}$ ккал/моль \\
\hline (Ac)Co(Im)P & $1.47 \pm 0.12$ & 169.36 \\
$(\mathrm{Ac}) \mathrm{Co}(2-\mathrm{MeIm}) \mathrm{P}$ & $0.52 \pm 0.032$ & 173.06 \\
$(\mathrm{Ac}) \mathrm{Co}(\mathrm{Py}) \mathrm{P}$ & $0.25 \pm 0.15$ & 162.79 \\
$(\mathrm{Ac}) \mathrm{Co}(\mathrm{Hi}) \mathrm{P}$ & $0.068 \pm 0.0057$ & 168.72 \\
$(\mathrm{Ac}) \mathrm{Co}(\mathrm{DMF}) \mathrm{P}$ & $0.011 \pm 0.001$ & 142.92 \\
\hline
\end{tabular}

Установлено также, что величина $K_{\mathrm{p}}$ комплексов $(\mathrm{Ac}) \mathrm{Co}(\mathrm{L}) \mathrm{P}$ увеличивается прямо пропорционально росту величины смещения $B$ полосы $(\Delta \lambda)$ (Рисунок 4$)$. Корреляционное уравнение имеет вид: $\lg K_{\mathrm{p}}=0.262 \cdot \Delta \lambda-$ $4.28(\mathrm{r}=0.98)$.

Сравнивая устойчивость молекулярных комплексов исследуемого порфирината кобальта и 5,15-ди(ортонитрофенил)-2,8,12,18-тетраметил-3,7,13,17-тетрабутилпорфирината кобальта, ${ }^{[17]}$ следует отметить, что наличие электроноакцепторных нитро-групп в фенильных фрагментах приводит к росту устойчивости молекулярных комплексов. Для обоих комплексов деформационные искажения макроцикла соизмеримы (Рисунок 5a), поэтому электронный фактор остается приоритетным и создает условия для существования достаточного эффективного заряда на металле, чтобы

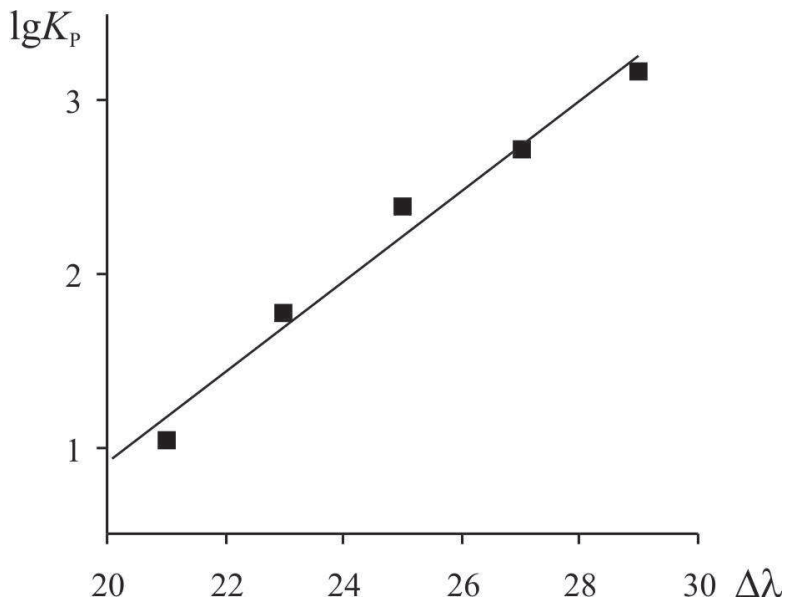

Рисунок 4. Зависимость $K_{\mathrm{p}}$ комплексов (Ac)(L)CoР от величины смещения основных полос поглощения ЭСП.

образовывать прочную связь с атомом азота основания $\left(\mathrm{Co}-\mathrm{N}_{\mathrm{L}}\right)$ по сравнению с исследуемым соединением. Следует отметить, что устойчивость молекулярных комплексов цинкового аналога ${ }^{[18]}$ также существенно выше, чем у (Ac)Co(L)P. Причина, в данном случае, во влиянии природы атома металла, наличия ацидо-лиганда и в высокой степени деформации макроцикла последнего (Рисунок 5a).

Наличие и степень деформации исследуемого порфирината кобальта и его молекулярных комплексов оценивали на основании расчетных данных, полученных квантово-химическим методом РМЗ. Из установленных характеристик следует, что молекула (Аc)СоР непланарна и имеетпреимущественно седлообразный тип деформации (Рисунки 5, 6). Координационный центр представляет собой тетрагональную пирамиду, в основании которой находится ромб, что соответствует рентгеноструктурным данным. ${ }^{[12]}$ Среднее значение отклонения скелетных атомов макроцикла от его средней плоскости (XY) по оси $\mathrm{Z}\left(\Delta \mathrm{Z}_{\mathrm{cp}}\right)$ составляет $0.400 \AA$, для сравнения, у цинкового аналога и нитро-замещенного порфирината кобальта величина $\Delta Z_{\text {ср }} 0.058 \AA$ и $0.417 \AA$, соответственно.

Из анализа геометрических и энергетических характеристик (Таблица 2, Рисунки 5, 6) следует, что 


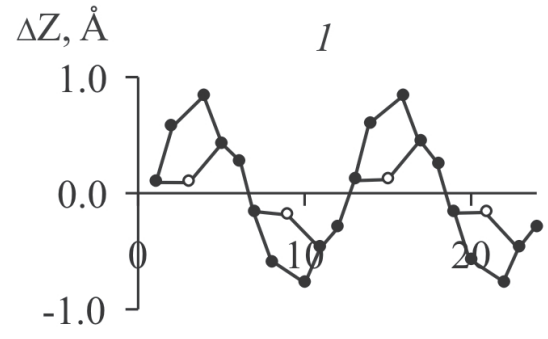

№ атома

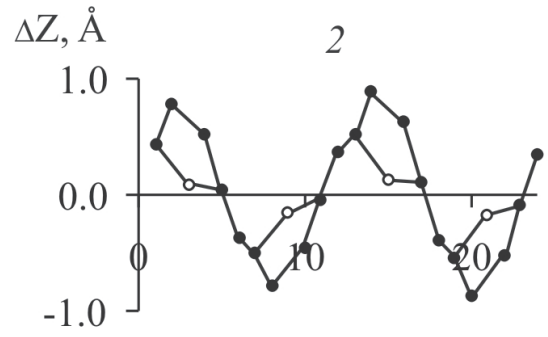

№ атома $\triangle \mathrm{Z}, \AA$

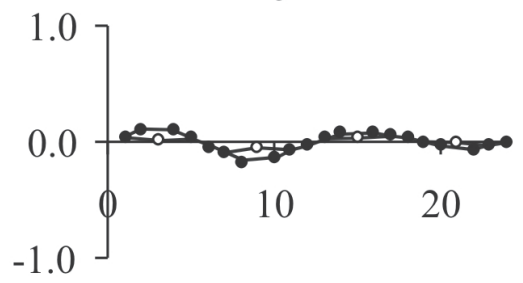

№ атома

$\Delta Z, \AA$

(Ac) $\operatorname{Co}(\operatorname{Im}) \mathrm{P}$

$\Delta \mathrm{Z}, \AA$

(Ac)Co(Py)P

$\Delta Z, \AA$

(Ac) Co(2-MeIm)P
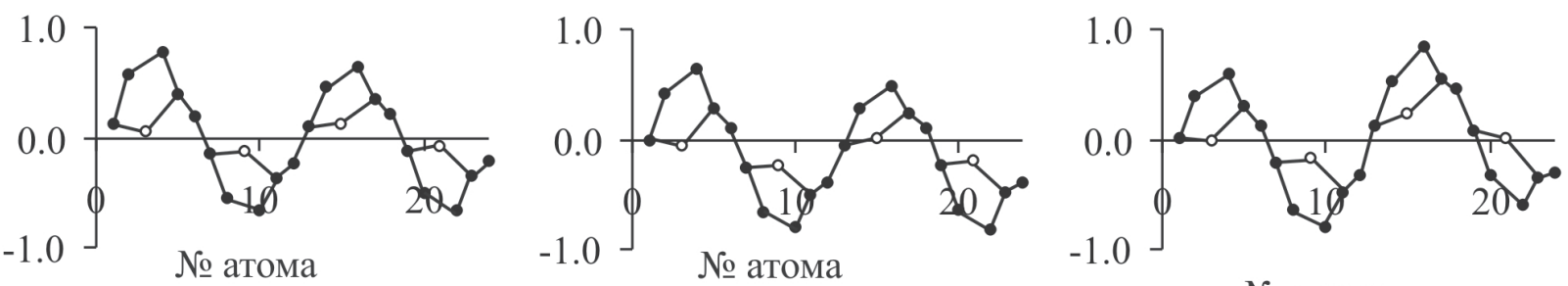

№ атома

\section{$\Delta \mathrm{Z}, \AA \quad$ (Ac) $\mathrm{Co}(\mathrm{DMF}) \mathrm{P}$}

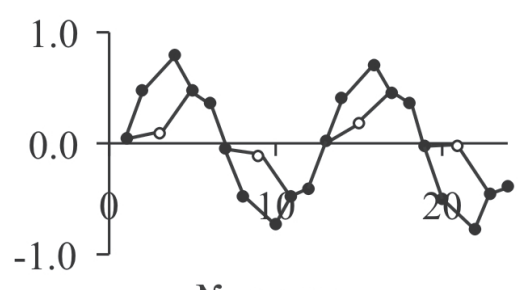

№ атома

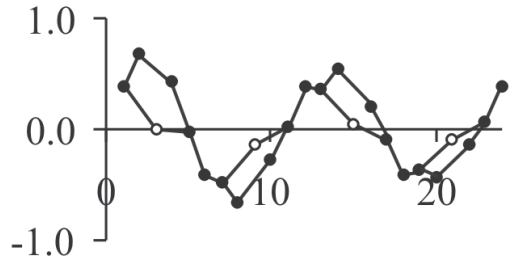

№ атома
$\Delta \mathrm{Z}, \AA \quad(\mathrm{Ac})(\mathrm{Im}) \mathrm{CoP}$

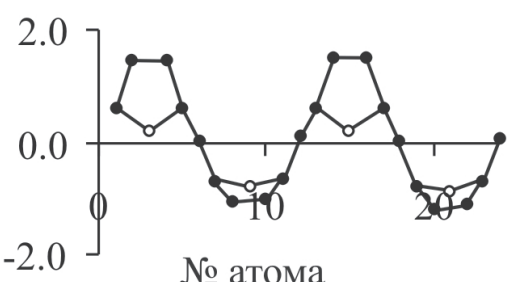

$\Delta \mathrm{Z}, \AA$

(Ac)(Py)CoP

$\Delta \mathrm{Z}, \AA$

(Ac)(2-MeIm)CoP

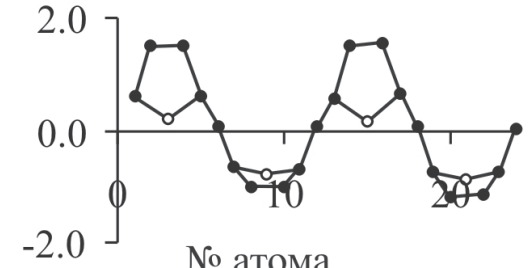

№ атома

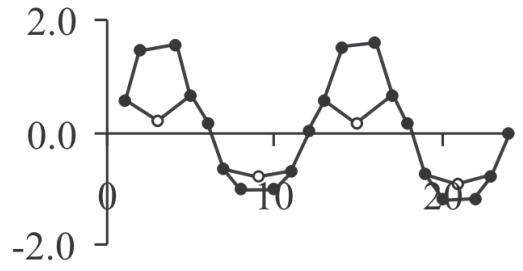

№ атома

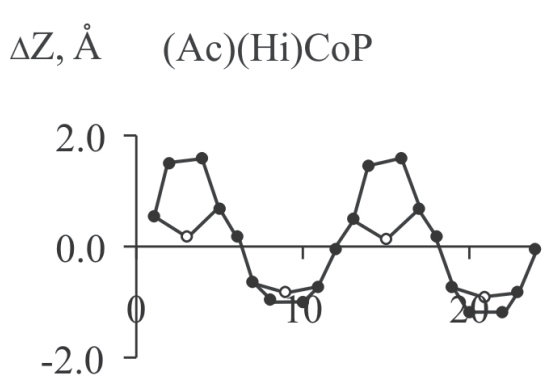

№ атома $\triangle \mathrm{Z}, \AA \quad(\mathrm{Ac})(\mathrm{DMF}) \mathrm{CoP}$

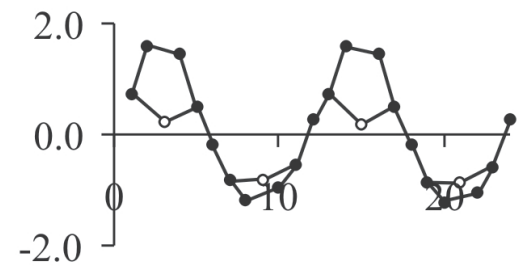

№ атома

б

Рисунок 5. Отклонение от средней плоскости порфиринового макроцикла его о скелетных атомов $(\Delta Z)$ для комплексов: $a)$ 1 - 5,15-дифенил-2,8,12,18-тетраметил-3,7,13,17-тетрабутилпорфиринат кобальта ацетата, 2 - 5,15-ди(орто-нитрофенил)2,8,12,18-тетраметил-3,7,13,17-тетрабутилпорфиринат кобальта ацетата и 3 - 5,15-дифенил-2,8,12,18-тетраметил-3,7,13,17тетрабутилпорфиринат цинка; б) (Ac)(L)CoР и (Ac)Co(L)P по данным квантово-химического расчета методом РM3; ○ - атомы азота, •- атомы углерода. 
Таблица 2. Некоторые геометрические и энергетические характеристики (Ас)СоР и его молекулярных комплексов.

\begin{tabular}{|c|c|c|c|c|c|c|c|}
\hline \multirow{3}{*}{ Комплекс } & \multirow{3}{*}{$\begin{array}{c}-E_{\text {св Со-L }}, \\
\text { ккал/моль }\end{array}$} & \multicolumn{6}{|c|}{ Длина связи, А̊ } \\
\hline & & $\mathrm{Co}-\mathrm{N}_{1}$ & $\mathrm{Co}-\mathrm{N}_{2}$ & $\mathrm{~N}_{1}-\mathrm{N}_{3}$ & $1_{\mathrm{Co}-\mathrm{L}}$ & $\mathrm{Co}-\mathrm{Ct}$ & $\mathrm{P}^{*}$ \\
\hline & & $\mathrm{Co}-\mathrm{N}_{3}$ & $\mathrm{Co}-\mathrm{N}_{4}$ & $\mathrm{~N}_{2}-\mathrm{N}_{4}$ & & & \\
\hline \multirow[t]{2}{*}{ (Ac)CoP } & & 1.927 & 1.924 & 3.861 & & 0.302 & 10.887 \\
\hline & & 1.933 & 1.921 & 3.797 & & & \\
\hline \multirow[t]{2}{*}{$(\mathrm{Ac}) \mathrm{Co}(\mathrm{Im}) \mathrm{P}$} & 67.83 & 1.949 & 1.947 & 3.895 & 1.935 & 0.098 & 11.032 \\
\hline & & 1.951 & 1.945 & 3.887 & & & \\
\hline \multirow[t]{2}{*}{$(\mathrm{Ac})(\mathrm{Im}) \mathrm{CoP}$} & 73.23 & 1.928 & 1.958 & 3.845 & 1.930 & 0.175 & 10.678 \\
\hline & & 1.932 & 1.957 & 3.069 & & & \\
\hline \multirow[t]{2}{*}{ (Ac)Co(2-MeIm)P } & 62.41 & 1.941 & 1.945 & 3.882 & 1.946 & 0.118 & 11.018 \\
\hline & & 1.948 & 1.948 & 3.890 & & & \\
\hline \multirow[t]{2}{*}{$(\mathrm{Ac})(2-\mathrm{MeIm}) \mathrm{CoP}$} & 71.28 & 1.923 & 1.9593 & 3.843 & 1.949 & 0.182 & 10.666 \\
\hline & & 1.937 & 1.9563 & 3.046 & & & \\
\hline \multirow[t]{2}{*}{ (Ac) $\mathrm{Co}(\mathrm{Py}) \mathrm{P}$} & 58.76 & 1.948 & 1.950 & 3.889 & 1.951 & 0.122 & 11.035 \\
\hline & & 1.947 & 1.951 & 3.899 & & & \\
\hline \multirow[t]{2}{*}{$(\mathrm{Ac})(\mathrm{Py}) \mathrm{CoP}$} & 67.23 & 1.934 & 1.955 & 3.850 & 1.959 & 0.197 & 10.657 \\
\hline & & 1.936 & 1.958 & 3.057 & & & \\
\hline \multirow[t]{2}{*}{$(\mathrm{Ac}) \mathrm{Co}(\mathrm{Hi}) \mathrm{P}$} & 57.40 & 1.936 & 1.939 & 3.888 & 1.988 & 0.139 & 11.020 \\
\hline & & 1.932 & 1.947 & 3.884 & & & \\
\hline \multirow[t]{2}{*}{$(\mathrm{Ac})(\mathrm{Hi}) \mathrm{CoP}$} & 61.95 & 1.926 & 1.961 & 3.852 & 1.964 & 0.205 & 10.644 \\
\hline & & 1.949 & 1.957 & 3.024 & & & \\
\hline \multirow[t]{2}{*}{ (Ac)Co(DMF)P } & 42.28 & 1.957 & 1.947 & 3.887 & 2.117 & 0.143 & 11.037 \\
\hline & & 1.941 & 1.952 & 3.897 & & & \\
\hline \multirow[t]{2}{*}{$(\mathrm{Ac})(\mathrm{DMF}) \mathrm{CoP}$} & 59.66 & 1.934 & 1.942 & 3.842 & 2.007 & 0.248 & 10.615 \\
\hline & & 1.926 & 1.943 & 3.012 & & & \\
\hline
\end{tabular}

*периметр координационной плоскости $\mathrm{N}_{4}$

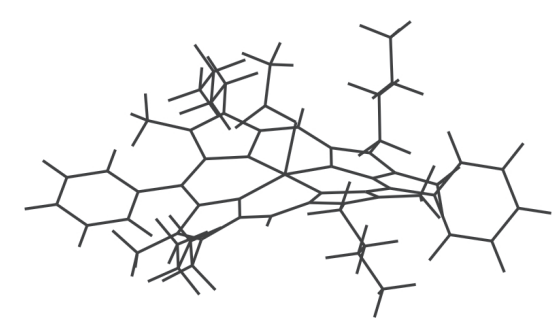

(Ac) $\mathrm{CoP}$

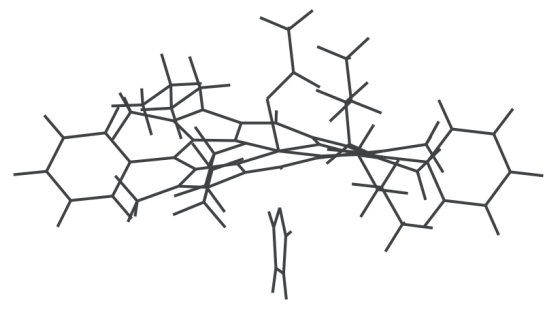

(Ac) $\operatorname{Co}(\mathrm{Im}) \mathrm{P}$

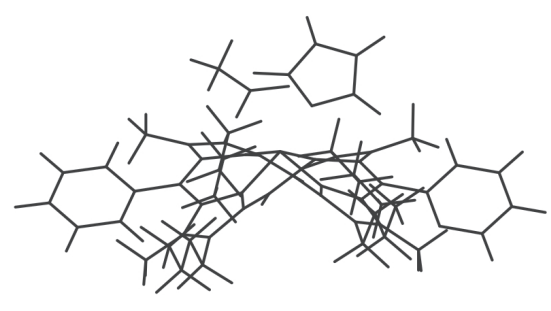

(Ac) $(\operatorname{Im}) \mathrm{CoP}$

Рисунок 6. Структура (Ас)СоР и его молекулярных комплексов с имидазолом, с разной ориентацией основания, рассчитанная квантово-химическим методом РМ3.

молекулярный комплекс соответствует составу $1: 1$. Основание может быть координировано как в транс$((\mathrm{Ac}) \mathrm{Co}(\mathrm{L}) \mathrm{P})$, так и в циис-положение $((\mathrm{Ac})(\mathrm{L}) \mathrm{CoP})$ по отношению к ацидо-лиганду (Рисунок 6). Значения энергии связи атома кобальта с атомом азота основания $\left(E_{\mathrm{cв}}\right)$ и величины этой связи $\left(1_{\mathrm{Co-}-\mathrm{L}}\right)$ для двух видов молекулярных комплексов с различной ориентацией основания отличаются несущественно. Однако, небольшой выигрыш в энергии $E_{\text {св }}$ и в значениях $1_{\text {Со-L }}$ наблюдается для комплексов с щ̧ис-ориентацией лигандов L и Ас (Таблица 2).

Образование молекулярных комплексов приводит к изменению степени деформации макроцикла. При цис-ориентации основания наблюдается существенный рост стерических напряжений порфиринового лиганда (Таблица 2, Рисунки 5б, 6). 

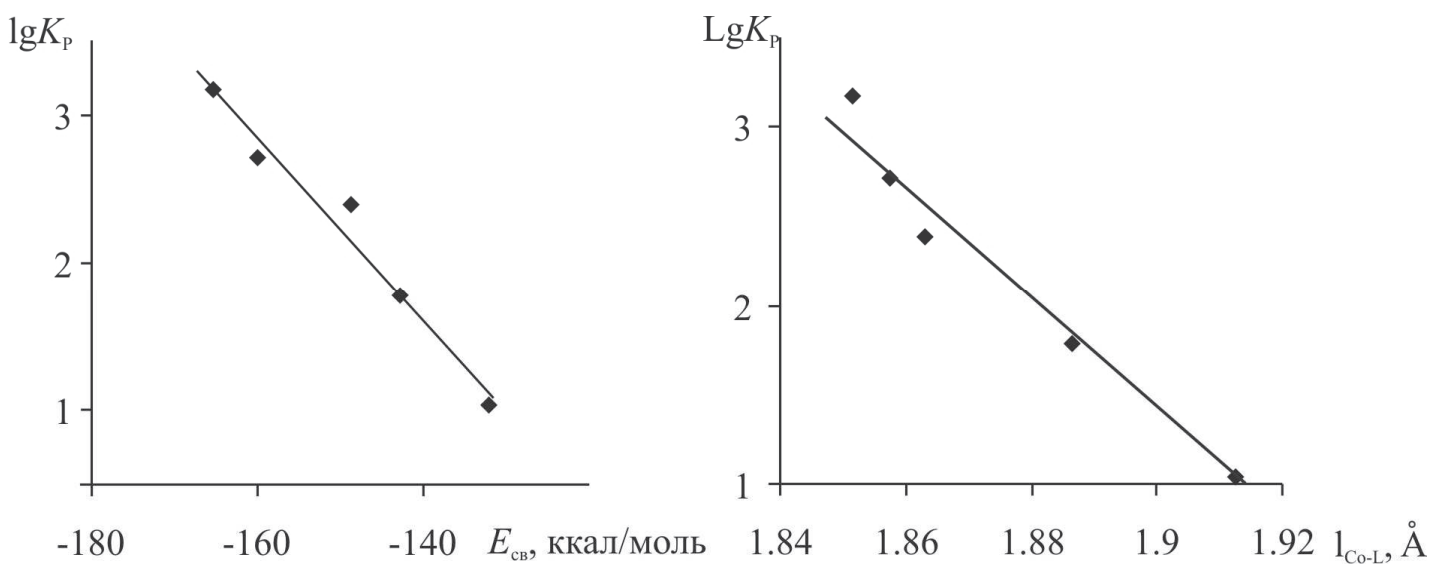

Рисунок 7. Зависимость устойчивости комплексов (Ac)(L)СoР от их расчетных характеристик, полученных методом РМ3.

Получена линейная корреляция между величиной связи атома кобальта с атомом азота основания и устойчивостью комплекса. Она описывается уравнением: $\lg K_{\mathrm{p}}=-32.52 \cdot \mathrm{l}_{\text {Со-L }}+63.18(\mathrm{r}=0.97)($ Рисунок 7).

Сравнение расчетных энергий связи Co-L в молекулярных комплексах $\left(E_{\mathrm{cs}}\right)$ (Таблицы 1,2$)$ со значениями констант равновесия показывает, что, чем отрицательнее значение энергии связи, тем устойчивее комплекс. Установленная линейная зависимость описывается корреляционным уравнением: $\lg K_{\mathrm{p}}=$ $-0.062 \cdot E_{\text {св }}-7.013(\mathrm{r}=0.97)$ (Рисунок 7). Таким образом, значения $E_{\text {св }}$ и $1_{\text {Co-L }}$ могут служить количественной характеристикой устойчивости в ряду молекулярных комплексов исследуемого порфирината кобальта.

\section{Заключение}

Установленные закономерности процесса межмолекулярного взаимодействия позволяют получить оценочные критерии устойчивости комплексов и выявить факторы, влияющие на координационные свойства порфирината кобальта.

Признательность. Работа выполнена при поддержке НТП "Научные и научно-педагогические кадры инновационной России на 2009 - 2012 годы." ГК № 02.740.11.0106, Программы фундаментальных исследований РАН «Теоретическое и экспериментальное изучение природы химической связи и механизмов важнейших химических реакций и процессов» и Российского фонда фундаментальных исследований (проект № 09-03-00736-a, 11-03-00993-а.).

\section{Список литературы}

\section{References}

1. Koifman O.I., Mamardashvili H.Zh., Antipin I.S. Sinteticheskie retseptory na osnove porfirinov $i$ ikh konyugatov s kaliks(4) arenamy [Synthetic Receptors on the Basis of Porphyrins and their Conjugates with Calix(4)arenes]. Moskva: Nauka, 2006. 246 p. (in Russ.).

2. Nevrova O.V., Lobanov A.V., Komissarov G.G. Macroheterocycles 2009, 2, 264-267.

3. Antonova N.A., Osipova V.P., Kolyada M.N., Movchan N.O., Milaeva E.R., Pimenov Y.T. Macroheterocycles 2010, 3, 139144.

4. Bulatov M.I., Kalinkin I.P. Prakticheskoe rukovodstvo po fotokolorimetricheskim i specktrofotometricheskim metodam analiza [Practical Guidance on Methods of Photocalorimetric and Spectrophotometric Analytical Methods]. L.: Khimiya, 1968. 183 p. (in Russ.).

5. Stewart J.J P. J. Comput. Chem. 1989, 10, 209-220.

6. Stewart J J.P. J. Comput. Chem. 1989, 10, 221-264.

7. Stewart J.J.P. J. Computer-Aided Mol. Des. 1990, 4, 1-105.

8. Fletcher R. Methods of Optimization. New York: John Wiley \& Sons, 1980. p. 10-29.

9. Zaitseva S.V., Zdanovich S.A., Semeikin A.S., Koifman O.I. Zh. Obsch. Khim. 2008, 78, 508-517 (in Russ.).

10. Granovsky A.A. http://classic.chem.msu.su/gran/gamess/ index.html.

11. Schmidt M.W., Baldridge K.K., Boatz J.A., Elbert S.T., Gordon M.S., Jensen J.H., Koseki S., Matsonaga N.,. Nguyen K.A., Su S., Windus T.L., Dupuis M., Montgomery J.A. J. Comput. Chem. 1993, 14, 1347-1363.

12. Porfiriny: Struktura, Svoistva, Sintez [Porphyrins: Structure, Properties, Synthesis] (Enikolopyan N.S., Ed.). Moskva: Nauka, 1985. 333 p. (in Russ.).

13. Comprehensive Organic Chemistry (Barton D., Oliss W.D., Eds.). Russ. transl., Moskva: Khimiya, 1981, Vol. 1., 736 p.; 1982, Vol. 2, 856 p.; Vol. 8, 752 p.

14. Mamardashvili N.Zh., Semeikin A.S., Golubchikov O.A. Zh. Org. Khim. 1993, 29, 1213-1223 (in Russ.).

15. Tables of Rate Constants and Equilibria of Homolytic Organic Reactions. Moskva: VINITI, 1976, Vol. 2, 706 p. (in Russ.).

16. Reichardt K. The Solvents and Medium Effects in Organic Chemistry. Russ. transl., Moskva: Mir, 1991. 76 p.

17. Zaitseva S.V., Zdanovich S.A., Koifman O.I. In: "XXIV International Chugaev Conference on Coordination Chemistry". St. Petersburg, June 15-19, 2009, p. 274.

18. Tolikina M.D., Zaitseva S.V., Zdanovich S.A. In: " $X$ International Conference on Physical and Coordination Chemistry of Porphyrins and their Analogs", Ivanovo, July 1-4, 2009, p. 166. 